\title{
Formação Continuada e Cultura Profissional: a educação algébrica e os movimentos de reorientação curricular no Estado de São Paulo
}

\author{
Antonio Marcos Emiliano \\ Professor, SEE-SP \\ antonioemiliano@prof.educacao.sp.gov.br \\ Maria Elisabette Brisola Brito Prado \\ Professora, UNIAN/SP \\ bette.prado@gmail.com

\section{Ruy Cesar Pietropaolo} \\ Professor, UNIAN/SP \\ rpietropaolo@gmail.com
}

\begin{abstract}
Resumo
O texto apresenta um projeto de investigação em desenvolvimento, que tem como objetivo verificar se o Currículo Oficial de Matemática do Estado de São Paulo, implementado em 2008, conseguiu provocar as necessárias transformações na cultura profissional dos professores de Matemática, em relação ao ensino da álgebra escolar. O estudo está inserido no contexto do curso Currículo e Prática Docente - Matemática - 2012, ofertado pela Secretaria de Estado da Educação. Quanto à técnica para coleta de dados, trata-se de uma pesquisa documental, pois considera os registros textuais dos professores, documentados em Ambiente Virtual de Aprendizagem. Os resultados preliminares revelaram, iluminados pelos trabalhos de Usiskin, Lins e Gimenez, Shulman e de Zeichner, que os professores se apoiam em diferentes concepções de educação algébrica para ensinar álgebra na $6^{\mathrm{a}}$ série $/ 7^{\circ}$ ano do Ensino Fundamental. Entretanto, não são todos os professores que inter-relacionam essas diferentes concepções a fim de tentar garantir o necessário desenvolvimento do pensamento algébrico nos estudantes.
\end{abstract}

Palavras-chave: Educação algébrica. Concepções de educação algébrica. Atividade algébrica. Aprendizagem algébrica com significado. Formação continuada de professores.

\section{Ongoing Training and Professional Culture: the algebraic culture and curricular redirection in São Paulo State}

\begin{abstract}
This paper presents a current investigation, which aims to verify if the Official Mathematics Curriculum of São Paulo State, introduced in 2008, was able to trigger the necessary changes on the professional culture among the Math teachers on the subject of the school algebraic. The study is placed in the context of the course Curricula and Teaching Practice - Mathematics - 2012, offered
\end{abstract}


by São Paulo State Education Secretariat. Regarding to the technics used to gather the data, this work leans to a documental research, since it considers the textual registers left by the teachers in Virtual Learning Environment. Preliminary data reveals, in the light of the works of Usiskin, Lins and Gimenez, Shulman and Zeichner, that teachers support themselves in different algebraic education conceptions to teach algebra on 6thgrade/7th year of Elementary School. However, not all teachers interrelate those different conceptions on the purpose of assure the necessary development of algebraic thinking of the students.

Keywords: Algebraic education. Algebraic education conceptions. Algebraic activity. Algebraic learning with significance. Ongoing training of teachers.

\section{Introdução}

No Estado de São Paulo, com a Proposta Curricular de Matemática do $1^{\circ}$ grau $^{1}$, elaborada pela Coordenadoria de Estudos e Normas Pedagógicas ${ }^{2}$, a Secretaria da Educação propôs, a partir de 1986, a implantação de um novo modelo pedagógico para o Ensino Fundamental, tendo em vista a construção da autonomia pedagógica do professor e o respeito ao ritmo individual e aos processos de maturação dos estudantes (SÃO PAULO, 1997).

Intrinsecamente ligada às discussões sobre a qualidade do ensino público no Estado de São Paulo, a elaboração da Proposta Curricular de Matemática do $1^{\circ}$ grau teve como ponto de partida o diagnóstico de problemas no ensino da Matemática, denunciado por muitos professores insatisfeitos com tal situação (SÃO PAULO, 1997). Sua elaboração buscou provocar profundas mudanças no cotidiano da sala de aula e visou atingir duas grandes metas estabelecidas para o ensino da Matemática no Ensino Fundamental: aplicar o conhecimento matemático de forma prática e desenvolver o raciocínio lógico nos estudantes (SÃO PAULO, 1997).

Apesar de inovações curriculares como essa buscarem orientar a prática docente dos professores, objetivando garantir o ensino de uma base comum de conhecimentos e competências vistos como indispensáveis para o enfrentamento dos desafios sociais, culturais e profissionais do mundo contemporâneo, verificou-se, ao final dos anos 90, que os diferentes movimentos de reorientação curricular ocorridos no Brasil, a partir dos anos 20, “[...] não tiveram força suficiente para mudar a prática docente dos professores para eliminar o caráter elitista desse ensino bem como melhorar sua qualidade" (BRASIL, 1998, p. 19).

No que se refere à álgebra, ficou evidenciado que a ênfase dada ao seu ensino não garantia o desenvolvimento do pensamento algébrico nos estudantes e nem seu sucesso em avaliações

\footnotetext{
${ }^{1}$ Com a Lei no 9.394 de 1996, o Ensino de Primeiro Grau passou a se chamar Ensino Fundamental (RIGOTTI, 2004).

${ }^{2}$ Atualmente denominada como Coordenadoria de Gestão da Educação Básica, a partir do Decreto n 57.141 , de 18 de julho de 2011.
} 
externas. Os resultados do SAEB, por exemplo, demonstraram que os itens relacionados à álgebra não atingiam um índice de acerto superior a 40\% em muitas regiões do país (BRASIL, 1998). Esses resultados acabavam por influenciar os professores que, na tentativa de elevar esses índices, propunham mais do mesmo, ou seja, "[...] apenas a repetição mecânica de mais exercícios" (BRASIL, 1998, p. 116). Além disso, em busca de tornar a aprendizagem algébrica mais significativa, alguns professores simplesmente deslocavam, de forma precoce, alguns conceitos algébricos tratados tradicionalmente no Ensino Médio, para o Ensino Fundamental (BRASIL, 1998).

Diante desse cenário bastante desfavorável para o ensino e para a aprendizagem da álgebra, há um razoável consenso de que, para garantir o desenvolvimento do pensamento algébrico nos estudantes, é preciso engajá-los em atividade algébrica que inter-relacione as diferentes concepções de educação algébrica (BRASIL, 1998).

A partir de 2008, com uma nova reforma curricular no Estado de São Paulo, que reestruturou a educação básica nos níveis Fundamental (anos finais) e Médio, a grade curricular relacionada à álgebra foi renovada e seu ensino foi proposto para ser iniciado, de forma organizada e intencional, na $6^{\mathrm{a}}$ série ( $7^{\mathrm{o}}$ ano), objetivando dar sentido e significado para o uso de letras na Matemática (SÃO PAULO, 2009).

Ao seguir uma linha de desenvolvimento da álgebra nos currículos de Matemática da Educação Básica, apresentaremos alguns resultados de pesquisa que buscam verificar se o movimento de reorientação curricular ocorrido no Estado de São Paulo, em 2008, conseguiu provocar as necessárias transformações na cultura profissional dos professores de Matemática, em relação ao ensino da álgebra escolar. Para que tal fim seja alcançado, analisaremos as diferentes concepções de educação algébrica que norteiam o trabalho de um grupo de professores de Matemática, participantes de um programa de formação continuada oferecido pela Secretaria da Educação do Estado de São Paulo, no ano de 2012.

\section{A Educação Algébrica e os Movimentos de Reorientação Curricular: Diferentes Finalidades da Álgebra nos Currículos de Matemática}

Atualmente, no âmbito da Educação Básica, a Educação Algébrica vem sendo muito discutida na Base Nacional Comum Curricular, na qual se propõe objetivos básicos de aprendizagem em Matemática, desde a Educação Infantil, passando pelo Ensino Fundamental (anos iniciais e finais), até chegar ao Ensino Médio. 
Diferentemente dos Parâmetros Curriculares Nacionais, nos quais houve consenso a respeito dos currículos de Matemática contemplarem o estudo de diferentes conteúdos em quatro eixos, Números e Operações (no campo da aritmética e da álgebra), Espaço e Forma (no campo da geometria), Grandezas e Medidas (interligando diferentes campos) e Tratamento da Informação (no campo da estatística, das probabilidades e da combinatória), a Base Nacional Comum Curricular prevê a organização dos objetivos de aprendizagem e cinco eixos: Geometria, Grandezas e Medidas, Estatística e Probabilidade, Números e Operações, Álgebra e Funções.

Observa-se, a partir dessa nova organização, que a ênfase dada ao eixo Números e Operações, diferentemente do que foi previsto nos Parâmetros Curriculares Nacionais, recai sobre o desenvolvimento do senso numérico, enquanto que no eixo Álgebra e Funções é dada ênfase ao desenvolvimento do pensamento algébrico. Mesmo havendo essa diferenciação, “[...] estão previstas conexões entre os conhecimentos de diferentes eixos e de diferentes componentes curriculares de modo que o/a estudante possa perceber a riqueza dos conhecimentos" (BRASIL, 2015, p. 120).

No Estado de São Paulo, nas Propostas Curriculares de Matemática apresentadas em 1986 e em 2008, há alguns pontos de divergência em relação ao lugar da álgebra em cada Currículo. Na Proposta Curricular de 1986, por exemplo, foram priorizadas a organização e distribuição dos conteúdos em três blocos temáticos: Números, Geometria e Medidas. O conteúdo álgebra foi proposto para ser explorado no tema "Números".

Na Proposta Curricular de 2008 foram priorizadas, em um primeiro momento, a organização e distribuição dos conteúdos nos blocos temáticos: Números, Geometria, Grandezas e Medidas e Tratamento da Informação. Ao deixar de ser apresentado como Proposta, a partir de 2010, o documento básico recebeu a denominação "Currículo do Estado de São Paulo", no qual prevaleceu a organização dos conteúdos em três grandes temas: Números, Geometria e Relações (SÃO PAULO, 2010, 2011, 2012). Nesse caso, as principais ideias associadas à álgebra são tratadas nos temas "Relações" e "Números", apesar de serem exploradas no tema "Geometria”, com "[...] uma permanente aproximação com a geometria analítica desde a apresentação do plano cartesiano, na primeira metade do Ensino Fundamental" (SÃO PAULO, 2012, p. 41).

Outro ponto importante em relação a essas duas Propostas (1986 e 2008) está relacionado às finalidades da álgebra em cada Currículo, conforme demonstrado no Quadro 1.

Quadro 1 - Finalidades da álgebra em cada Proposta Curricular de Matemática do Estado de São Paulo

\begin{tabular}{|c|l|}
\hline \multicolumn{1}{|c|}{ Proposta Curricular de Matemática - 1986 } & \multicolumn{1}{c|}{ Proposta Curricular de Matemática - 2008 } \\
\hline $\begin{array}{l}\text { - Álgebra como suporte para a operação com } \\
\text { números de modo genérico, sem referência imediata }\end{array}$ & $\begin{array}{l}\text { - Álgebra como suporte para ampliar o escopo da } \\
\text { linguagem numérica, entendida como instrumento de }\end{array}$ \\
\hline
\end{tabular}


a contagens ou medidas.

- Álgebra vinculada aos temas: estudo das propriedades das operações e regras de simplificação no cálculo com potências.

- Busca-se um entendimento das letras como generalizações das operações e propriedades dos números.

- Busca-se, sobretudo, o desenvolvimento de técnicas para resolução de equações.

- O desenvolvimento do pensamento algébrico é explorado como foco principal quase que exclusivamente no tema Números.

- Álgebra associada ao Cálculo Literal. O título "Álgebra" foi substituído pelo título "Cálculo Literal” (SÃO PAULO, 1997, p. 121). representação simbólica, tornando-a cada vez mais rica e abrangente.

- Álgebra vinculada a diferentes temas.

- Busca-se a compreensão do uso de letras no sentido de incógnita e de variável e a generalização de procedimentos aplicados nos cálculos aritméticos.

- Busca-se, sobretudo, o desenvolvimento de ideias relativas às funções, por meio de situações envolvendo a proporcionalidade, além do desenvolvimento de ideias relacionadas à generalização de regularidades. As técnicas relacionadas ao cálculo literal são valorizadas, principalmente o movimento conceitual de resolução.

- O desenvolvimento do pensamento algébrico é explorado como foco principal quase que exclusivamente nos temas Números e Relações.

- Álgebra como representação de regularidades por meio da linguagem simbólica Matemática.

Fonte: Elaborado pelos autores.

Para Lins e Gimenez (1997), as diferentes finalidades da álgebra, como as definidas em cada Proposta (Quadro 1), têm sua raiz nas diferentes conceitualizações da atividade algébrica. Para Usiskin (1995), as diferentes concepções da álgebra é que acabam por definir sua finalidade nos currículos da escola média. Em outras palavras, são as diferentes visões do que vem a ser a atividade algébrica que definem quais são as finalidades da álgebra nos currículos da educação básica e quais conteúdos devem ser priorizados, a fim de promover a educação algébrica dos estudantes.

A definição das finalidades da álgebra em cada Proposta Curricular de Matemática do Estado de São Paulo (1986 e 2008) sugeriu que o primeiro contato com o uso de letras na Matemática devesse ocorrer na $6^{\mathrm{a}}$ série $\left(7^{\mathrm{o}}\right.$ ano) do Ensino Fundamental. Evidentemente que se trata, apenas, de uma proposta formalizada nos documentos, não impedindo que as atividades envolvendo o uso de letras pudessem ser aplicadas em momento anterior a essa série, desde que os professores julgassem adequado, frente à maturidade dos estudantes. Os conteúdos priorizados para realização desse primeiro contato com o uso de letras na Matemática podem ser visualizados no Quadro 2.

Quadro 2 - Temas e conteúdos priorizados para iniciar o primeiro contato com o uso de letras na Matemática, na $6^{\mathrm{a}}$ série ( $7^{\circ}$ ano), em cada Proposta Curricular de Matemática do Estado de São Paulo

\begin{tabular}{|c|c|}
\hline Proposta Curricular de Matemática - 1986 & Proposta Curricular de Matemática - 2008 \\
\hline $\begin{array}{l}\text { Tema: Números } \\
\text { - Cálculo literal: } \\
\text { ○ Noções de cálculo literal. } \\
\text { ○ Soma algébrica e expressões algébricas. } \\
\text { ○ Multiplicações de expressões algébricas. } \\
\text { ○ Divisão de monômios. }\end{array}$ & $\begin{array}{l}\text { Tema: Números } \\
\text { - Álgebra: } \\
\text { ○ Uso de letras para representar um valor } \\
\text { desconhecido. } \\
\text { o Conceito de equação. } \\
\text { o Resolução de equações. }\end{array}$ \\
\hline
\end{tabular}




\begin{tabular}{|l|l|}
\hline$\circ$ Divisão de polinômios por monômios. & ○ Equações e problemas. \\
\hline
\end{tabular}

Fonte: Adaptado de São Paulo (1997, 2012).

Ao observarmos essa organização (Quadro 2), olhando pela ótica das diferentes interpretações da álgebra escolar ${ }^{3}$ (diferentes concepções de educação algébrica), definidas nos Parâmetros Curriculares Nacionais de Matemática, verificamos que foram priorizadas, na Proposta de 1986, como ponto de partida para o estudo da álgebra, as concepções "Aritmética Generalizada" e "Estrutural", sobretudo pelo fato de as atividades sugeridas no documento básico do Currículo explorarem a manipulação de expressões algébricas baseadas nas regras e propriedades dos números e o cálculo algébrico puramente abstrato, baseado na soma algébrica de polinômios, na multiplicação de monômios e na divisão de monômios e divisão de polinômios por monômios.

No caso da Proposta Curricular de 2008, verificamos que foram priorizadas as concepções "Aritmética Generalizada", "Equações" e "Funcional”, uma vez que as atividades sugeridas no Caderno do Professor ${ }^{4}$ exploram "[...] o uso de letras para representar valores desconhecidos, relações entre grandezas e padrões e regularidades numéricas" (SÃO PAULO, 2009, p. 9).

Nossa tese é que o trabalho que os professores desenvolvem na $6^{\mathrm{a}}$ série ( $7^{\circ}$ ano) do Ensino Fundamental, especificamente na rede pública estadual de São Paulo, é influenciado pelas diferentes concepções de educação algébrica que norteiam o ensino da álgebra em cada momento curricular. As diferentes finalidades da álgebra apresentadas em cada Proposta Curricular de Matemática (1986 e 2008) determinam, ou relacionam-se, com as diferentes concepções que os professores têm sobre o ensino da álgebra escolar. Resta saber se o trabalho que esses professores desenvolvem na $6^{\mathrm{a}}$ série ( $7^{\mathrm{o}}$ ano) do Ensino Fundamental, em relação ao primeiro contato com o uso de letras na Matemática, se embasa nas concepções de educação algébrica que norteiam o ensino da álgebra na Proposta de 1986 ou na Proposta de 2008.

\section{As Diferentes Concepções da Educação Algébrica: Breve Histórico}

Como afirmamos na seção anterior, as diferentes concepções de educação algébrica têm sua raiz no que se acredita ser a atividade algébrica (LINS; GIMENEZ, 1997). As diferentes conceitualizações da atividade algébrica, por sua vez, se fundamentam em propostas que buscam identificar se um sujeito está engajado ou não em atividade algébrica. Essa identificação pode estar embasa, por exemplo, em conteúdos (equações, cálculo literal, funções, etc.), em perspectivas históricas acerca

\footnotetext{
${ }^{3}$ Aritmética Generalizada; Funcional; Equações; e Estrutural (BRASIL, 1998).

${ }^{4}$ Conjunto de documentos que integram o documento básico do Currículo, a fim de completá-lo. Foram elaborados para orientar o trabalho dos professores no ensino dos conteúdos e a aprendizagem dos estudantes (SÃO PAULO, 2012).
} 
das notações algébricas (retraçando o seu desenvolvimento da álgebra ao longo da história) ou em álgebra puramente abstrata (como resultante da ação do pensamento formal).

Apesar dessa dessemelhança, o que há em comum entre essas diferentes conceitualizações da atividade algébrica é o fato de que, de alguma forma, todas apresentam propostas para a sala de aula, pois buscam “[...] produzir um 'mapa' do que é a correta atividade algébrica, mapa esse segundo o qual professores e desenvolvedores curriculares se orientariam [...]" (LINS; GIMENEZ, 1997, p. 104). Nessa perspectiva, os desenvolvedores curriculares acabam por elaborar os mapas (formas adequadas) para engajar os estudantes no que é tomado, corretamente, por atividade algébrica, ao passo que os professores utilizariam esses mapas buscando identificar o que os alunos sabem e onde precisam chegar (LINS; GIMENEZ, 1997).

Para Usiskin (1995, p. 12), algumas questões relacionadas ao currículo de álgebra, como a ênfase dada à aprendizagem de técnicas manipulatórias, bem como à definição do melhor momento para introdução do pensamento funcional, “[...] relacionam-se com as próprias finalidades do ensino e da aprendizagem de álgebra, com os objetivos da formação em álgebra e com as concepções que tenhamos desse corpo de conhecimentos."

Ao buscar definir o que é a álgebra da escola média - ou como dizemos: álgebra escolar -, Usiskin (1995) afirma que há uma distinta conotação entre a álgebra que é ensinada na educação básica com a álgebra que é ensinada na educação superior. Ao refletir sobre essa questão, ressaltando que a álgebra escolar está intimamente ligada à busca por dar sentido e significado para o uso de letras na Matemática, o autor defende a tese de que há uma relação mútua entre as diferentes propostas para a sala de aula com as distintas formas de utilização das variáveis. Por consequência, apresenta quatro concepções de educação algébrica que determinam as finalidades da álgebra escolar:

\section{Concepção 1 - A álgebra como aritmética generalizada}

A primeira concepção de educação algébrica definida por Usiskin (1995) caracteriza a atividade algébrica como uma expressão da generalidade ou generalizadora de modelos, como diz o autor. Nos Parâmetros Curriculares Nacionais de Matemática, essa concepção de educação algébrica é denominada "Aritmética Generalizada" e o uso que se faz das letras se resume a generalização de modelos aritméticos (BRASIL, 1998).

Tradicionalmente, nessa concepção de ensino, são veiculados conteúdos que tratam das regras e propriedades das operações realizadas com números, como sugerido na Proposta Curricular de Matemática de 1986. Na atualidade, a maior referência dessa concepção se baseia na procura e 
identificação de padrões e regularidades numéricas, conforme sugerido na Proposta Curricular de Matemática de 2008.

Concepção 2 - A álgebra como um estudo de procedimentos para resolver certos tipos de problemas

A segunda concepção de educação algébrica definida por Usiskin (1995) caracteriza a atividade algébrica como o estudo da simbologia e sua manipulação. Apresenta uma metodologia baseada no domínio de técnicas/algoritmos tomados como modelo para a resolução de equações. Segundo Lins e Gimenez (1997), a versão mais sofisticada dessa concepção está associada ao uso de balanças de dois pratos para ensinar algumas técnicas de resolução de equações, baseadas no conceito de equivalência, como ocorre na Proposta Curricular de 2008.

Nos Parâmetros Curriculares Nacionais de Matemática, essa concepção de educação algébrica é denominada "Equações” e as letras são consideradas como incógnitas (BRASIL, 1998). Para Usiskin (1995), as letras são consideradas incógnitas ou constantes.

\section{Concepção 3 - A álgebra como estudo de relações entre grandezas}

A terceira concepção de educação algébrica definida por Usiskin (1995) caracteriza a atividade algébrica pela exploração das relações entre grandezas. As relações matemáticas são representadas por letras cujos referenciais quantitativos variam a cada observação. Segundo Usiskin (1995), apenas no contexto dessa concepção é que surgem as noções de variáveis independente e dependente (conceito de interdependência entre duas ou mais grandezas). Na Proposta Curricular de 2008, por exemplo, essa concepção de ensino é explorada no estudo de algumas relações que se estabelecem nas principais fórmulas de diferentes áreas do conhecimento (Química, Física, Economia, etc.).

Nos Parâmetros Curriculares Nacionais de Matemática, essa concepção de educação algébrica é denominada "Funcional" e as letras são consideradas variáveis que expressam relações e funções. Para Usiskin (1995), as letras podem ser consideradas, também, como argumento (valores do domínio de uma função) ou parâmetro (um número do qual dependem outros números).

\section{Concepção 4 - A álgebra como estudo das estruturas}

A quarta e última concepção de educação algébrica definida por Usiskin (1995) caracteriza a atividade algébrica como o estudo das propriedades estruturais da álgebra. Apesar de envolver no ensino superior o estudo de grupos, anéis, corpos e ideais, a álgebra, como estudo das estruturas na escola média, é reconhecida pelas propriedades operatórias realizadas com números reais e expressões polinomiais (USISKIN, 1995). Em sua metodologia, o foco incide sobre a manipulação 
de variáveis de forma puramente abstrata, sem qualquer referência a quantidades, ou seja, por meio dessa concepção de educação algébrica deseja-se que os estudantes sejam capazes de operar com as variáveis sem ter que voltar ao nível dos referenciais quantitativos (USISKIN, 1995).

Na Proposta Curricular de 1986, recorreu-se a essa concepção de ensino, que tem como base a abstração, por conta da limitação de contextos que explicam como ocorre a maioria dos cálculos algébricos. Nos Parâmetros Curriculares Nacionais de Matemática, essa concepção de educação algébrica é denominada "Estrutural" e as letras são consideradas como símbolo puramente abstrato.

Algumas considerações sobre as diferentes concepções de educação algébrica

As diferentes concepções de educação algébrica definidas por Usiskin (1995) são importantes para entendermos quais estratégias os professores de Matemática adotam ao buscarem dar sentido e significado para o uso de letras na Matemática, como costumam engajar os estudantes em atividade algébrica, o que eles entendem por atividade algébrica e quais concepções embasam o seu trabalho. Essas questões, por sua vez, são importantes para compreendermos quais métodos são empregados pelos professores ao buscarem levar os estudantes a construírem ideias algébricas com significado. Mas o que vem a ser "construir ideias algébricas com significado", um tema tão central ao ensino da álgebra?

Segundo Lins e Gimenez (1997), o termo "significado" faz referência a um conjunto de coisas que se pode dizer, efetivamente, a respeito de um objeto no interior de uma atividade. Nessa perspectiva, construir ideias algébricas com significado implicaria formular um conjunto de afirmações que pudessem expressar, no interior da atividade algébrica, as principais ideias da álgebra. Atividade algébrica, então, pode ser entendida como o processo de produção de significados para a álgebra (LINS; GIMENEZ, 1997).

Para compreender como ocorre o processo de produção de significados para a álgebra que buscamos verificar se o atual Currículo do Estado de São Paulo conseguiu provocar mudanças na cultura profissional dos professores de Matemática, em relação à educação algébrica.

\section{Contexto e Aspectos Metodológicos}

A pesquisa está sendo desenvolvida no contexto do Curso Currículo e Prática Docente Matemática - 2012, um curso de formação continuada ofertado pela Secretaria da Educação do Estado de São Paulo, por meio da Escola de Formação e Aperfeiçoamento dos Professores "Paulo Renato Costa Souza" (EFAP). O curso teve início em 18 de agosto e foi finalizado em 11 de 
dezembro de 2012, sendo que o primeiro módulo avaliativo foi iniciado no dia 24, já que o período de 18 a 23 de agosto foi destinado ao módulo de apresentação do AVA-EFAP (SÃO PAULO, 2012a).

O curso foi desenvolvido na modalidade a distância, por meio de Ambiente Virtual de Aprendizagem da EFAP, e contou com a inscrição de 1.151 professores, distribuídos em 33 turmas (SÃO PAULO, 2016). A carga horária total foi equivalente a 260 horas e dividida em dois Núcleos: Básico e Específico.

O Núcleo Básico do curso foi composto por 3 módulos de 20 horas cada, totalizando 60 horas, e tratou de questões gerais como Currículo, Competências e Tecnologias; Acessibilidade e Diversidade; e Avaliação Externa (SARESP).

O Núcleo Específico, composto por 10 módulos de 20 horas cada, totalizando 200 horas, buscou apresentar o universo do Currículo do Estado de São Paulo para Matemática, de forma a auxiliar os professores na preparação do planejamento e na aplicação das situações de aprendizagem.

Os módulos foram compostos por atividades avaliativas como fóruns de discussão, questões objetivas e dissertativas e duas atividades de "Vivência", realizadas em sala de aula junto aos alunos. As atividades foram mediadas e avaliadas por professores tutores, com exceção das questões objetivas, avaliadas pela própria plataforma.

Para realização da pesquisa, os dados foram coletados do fórum de discussão do $6^{\circ}$ módulo (Núcleo Específico), intitulado "Álgebra I: do uso de letras às equações”. O referido módulo abordou os materiais de apoio (Cadernos do Professor e do Aluno) que visam subsidiar o trabalho dos professores de Matemática nas Situações de Aprendizagem que discutem algumas estratégias de ensino para a introdução do uso de letras na Matemática, na $6^{a}$ série $/ 7^{\circ}$ ano do Ensino Fundamental.

O plano de análise considerou os pressupostos metodológicos propostos por Bardin (1977). Para realização da análise categorial temática, recorremos a indicadores não frequenciais constituídos por índices que representam a presença (ou ausência) de concepções de educação algébrica nas narrativas dos professores.

As categorias de análise foram definidas a priori, assim como os pressupostos e os objetivos que nortearam a análise, todos orientados pelo referencial teórico que trata das diferentes concepções de educação algébrica que norteiam o ensino da álgebra na escola média (USISKIN, 1995). 


\section{Alguns Resultados da Análise dos Dados}

Os primeiros resultados da análise de conteúdo evidenciaram que as narrativas abordaram uma mesma unidade temática em diferentes níveis de detalhamento, apresentando um fator de dificuldade durante o processo de categorização. Para superar essa dificuldade inicial, foram definidos quatro níveis de análise, em cada um dos agrupamentos.

A definição de cada nível e um exemplo de narrativa podem ser observados a seguir:

- Nível 1: o primeiro nível é constituído pelas narrativas que fizeram referência a uma ou mais concepções de educação algébrica, mas sem relacionar aspectos da aprendizagem dos alunos e/ou detalhar estratégias de ensino.

\section{Exemplo de narrativa:}

"Acho importante explorar a ideia da balança, realmente fica fácil do aluno visualizar." (Prof_037; 22/10/2012 às 20:32).

- Nível 2: o segundo nível é constituído pelas narrativas que fizeram referência a uma ou mais concepções de educação algébrica, com ênfase nas dificuldades dos alunos.

\section{Exemplo de narrativa:}

"Nossos alunos tem grande dificuldade em transpor a linguagem habitual em linguagem algébrica, quando ensinamos só fórmulas, fica mais fácil eles aprenderem, conseguem assimilar [...], mas quando eles mesmo tem que colocar e 'desenvolver as fórmulas' digamos assim, eles possuem um bloqueio enorme, são poucos os alunos que conseguem." (Prof_006; 18/10/2012 às 19:31).

- Nível 3: o terceiro nível é constituído pelas narrativas que fizeram referência a uma ou mais concepções de educação algébrica, com ênfase nas estratégias e/ou as atividades que nortearam o ensino.

\section{Exemplo de narrativa:}

"Ao ensinar Álgebra, primeiro introduzo o conceito de variável representativa de números. As expressões usando estas variáveis são manipuladas usando regras de operações, aplicáveis a números, como adição. Estes conceitos podem ser usados, por exemplo, na resolução de equações. A adição e a multiplicação podem ser generalizadas e suas definições exatas conduzem a estruturas como grupos, anéis e corpos que são estudados na área de Matemática. Também começo com a introdução das sequências e expressões algébricas equivalentes, casos notáveis da multiplicação de binômios, noções de equações [...] resolução de equações do primeiro grau, problemas envolvendo equações do primeiro grau, etc.” (Prof_001 22/10/2012 às 23:18).

- Nível 4: o quarto e último nível é constituído pelas narrativas que fizeram referência a mais de uma concepção de educação algébrica, apresentando uma inter-relação entre essas diferentes abordagens.

\section{Exemplo de narrativa:}

"Para que os alunos interpretem a linguagem simbólica na Álgebra, é necessário que compreendam primeiro as generalizações possiveis em cada situação para, a partir daí, 
interpretar e utilizar determinada linguagem ou simbologia própria da Álgebra. Isto porque que podem explicar a estrutura de um cálculo algébrico sem utilizar nenhum tipo de linguagem própria da Álgebra, ou seja, explicar apenas descritivamente, por meio de frases ou textos que ele possa produzir para explicar algum tipo de cálculo. Assim, fica mais fácil estabelecer as relações entre as duas coisas: simbologia algébrica e generalização algébrica." (Prof_041; 22/10/2012 às 20:57).

Após a definição desses diferentes níveis, verificamos que as narrativas poderiam ser analisadas em até 15 agrupamentos, considerando o número de arranjos entre as quatro concepções de educação algébrica definidas por Usiskin (1995).

A análise individual das narrativas em cada agrupamento demonstrou que há uma grande tendência, por parte dos professores, à adoção de práticas tradicionais de ensino, já que a grande maioria fez referência à Concepção "Equações" (Agrupamento 2). Entretanto, trata-se de uma análise superficial e individualista das narrativas, podendo distorcer o verdadeiro resultado, levando à conclusão de que a reforma curricular ocorrida em 2008 no Estado de São Paulo não conseguiu mudar a prática docente dos professores, em relação ao ensino da álgebra.

Ao olharmos para os professores, explorando o contexto da discussão, ficou evidenciado que há uma preocupação em levar os estudantes a construírem ideias algébricas com significado, a partir de estratégias diversificadas de ensino.

No caso das narrativas inseridas no Nível 4, por exemplo, são apresentadas propostas de trabalho que inter-relacionam as diferentes concepções de educação algébrica, conforme demonstrado a seguir:

"Normalmente faço a introdução da álgebra descrevendo aos alunos sobre algo desconhecido e as
várias formas de nomeá-las e que podemos até dar valores a este desconhecido. Utilizo também
funçóes, quando temos um valor que depende e ou altera em relação a outro. Exemplo: A
quantidade de pão (x) em relação ao preço (fixo), que resulta em um outro valor (y). Neste
momento de iniciação à álgebra, procuro não usar termos matemáticos, pois primeiro gosto de dar
exemplos associados a realidade dos alunos, para somente depois utilizar uma linguagem
matemática. Num segundo momento começo as equaçóes com imagens/desenhos nos lugares das
letras. Para só depois troca-las e para ficar mais próxima a eles não faço o uso continuo das letras
x e y, peço a eles que escolham a primeira letra de seu nome ou a letra que eles querem colocar."
(Prof_024; 20/10/2012 às 7:57).

A narrativa em questão apresenta uma metodologia de ensino que privilegia a iniciação à álgebra pela exploração das relações entre grandezas, com vistas ao desenvolvimento do pensamento funcional (Concepção "Funcional”). Em um segundo momento privilegia-se um modelo pautado na aprendizagem de técnicas para resolução de equações (Concepção "Equações”). Esse tipo de abordagem não apresenta, apenas, uma preocupação com a linguagem algébrica enquanto objeto, mas, principalmente, com o desenvolvimento do pensamento funcional.

Na Proposta Curricular de 2008, sugere-se que o primeiro contato com o uso de letras na Matemática deva ocorrer pelo estudo dos padrões em figuras e em sequências numéricas 
(Concepção “Aritmética Generalizada”). Usiskin (1995) afirma que alguns educadores sugerem que a iniciação em educação algébrica deva ocorrer por meio da Concepção "Funcional", privilegiando o contexto das variáveis dependente e independente (modelo exclusivamente algébrico). Apesar dessa sugestão, Usiskin (1995) acrescenta que a notação funcional $(y=f(x))$, utilizada para representar a relação entre duas ou mais grandezas, pode confundir os estudantes. $\mathrm{O}$ autor explica que o fato se deve à função $f$ representar um número do qual dependem outros números (parâmetro da função).

Ao observarmos a explicação do professor, fica evidenciado que não há uma preocupação com a notação funcional, mas uma preocupação em envolver os estudantes em atividade algébrica que exige a organização de dados concretos e o estabelecimento de relações entre esses dados, sem se preocupar com métodos e técnicas de resolução. Nesse sentido, o uso de recursos técnicos para a resolução de equações é explorado em fase posterior, sendo algo secundário aos processos de ensino e aprendizagem da álgebra.

Esse exemplo de análise demonstra que é preciso olhar para o contexto da discussão e não apenas para a presença (ou ausência) de determinada concepção de educação algébrica, em narrativas isoladas. O principal fato se deve ao que evidenciamos ao realizar uma análise flutuante ${ }^{5}$ do contexto da discussão: é verdade que alguns professores apresentaram uma postura tradicional, mas outros apresentaram, em diferentes postagens, uma preocupação com o desenvolvimento dos estudantes ao estarem engajados em atividade algébrica, ou seja, alguns professores indicaram, em postagens isoladas, que adotam diferentes concepções de educação algébrica como estratégia de ensino. Ao seguirmos essa perspectiva, concluímos que é preciso se aprofundar ainda mais na análise dos dados para verificar, realmente, o que os professores pretendem promover por meio do ensino da álgebra.

\section{Considerações Finais}

Os dados aqui discutidos demonstram que os professores têm diferentes conhecimentos acerca das diferentes concepções de educação algébrica que norteiam o ensino da álgebra escolar. A análise das narrativas inseridas no Nível 4, por exemplo, indica que, a partir da reforma curricular que reestruturou a educação básica, em 2008, houve mudanças na prática docente de alguns professores, conforme amostra a seguir:

"No livro "ÁLGEBRA: DAS VARIÁVEIS ÀS EQUAÇÕES E FUNÇÕES" de Eliane Reame de Souza e Maria Ignez de Souza Vieira Diniz, CAEM - IME/USP cita que no ensino da álgebra na

\footnotetext{
${ }^{5}$ Primeiro contato com os documentos por meio de uma leitura rápida a fim de organizá-los (GIL, 2008).
} 
escola deve ser considerado quatro funções (ideias) distintas: 1- A Álgebra como generalizadora da aritmética [...] 2- A Álgebra como estudo de processos para resolução de problemas [...] 3- A Álgebra como expressão da variação de grandezas [...] 4- A Álgebra como estudo de estruturas matemáticas [...] Ao olharmos os cadernos do professor e do aluno podemos notar que estas funções (ideias) são tratadas no volume 4 da $6^{a}$ série $\left(7^{\circ}\right.$ ano), volumes 2 e 3 da $7^{a}$ série $\left(8^{o}\right.$ ano), volume 2 da $8^{a}$ série ( $9^{\circ}$ ano) e consolidando ao longo do Ensino Médio." (Prof_025; 14/10/2012 às 23:06).

Esse exemplo de narrativa demonstra a importância que a formação continuada tem para os processos de aprendizagem e desenvolvimento profissional da docência, devendo oferecer aos professores situações em que possam refletir sobre sua prática para compreendê-la e reconstruí-la, segundo os princípios da prática reflexiva de Zeichner (1993). Nesse sentido, a formação deve considerar os conhecimentos constituintes da prática docente, que, segundo Shulman (1987), envolve a integração do conhecimento do conteúdo específico, do conhecimento pedagógico do conteúdo e do conhecimento do currículo.

As considerações do professor, presentes neste último exemplo de narrativa, vão ao encontro dessa ideia, não apenas pela importância da reflexão como prática social (ZEICHNER, 1993), mas por destacar, também, quais concepções de educação algébrica devem nortear o ensino da álgebra escolar e como o seu desenvolvimento se consolida ao longo do Currículo. Acreditamos que, se olharmos para o contexto da discussão realizada pelos professores por meio de um estudo fundamentalmente qualitativo, encontraremos mais exemplos dessa tendência.

\section{Referências}

BARDIN, L. Análise de Conteúdo. Lisboa: Edições 70, 1977.

BRASIL. Ministério da Educação. Base Nacional Comum Curricular (documento preliminar). 2015. Disponível em: <http://basenacionalcomum.mec.gov.br/documentos/BNCC-

APRESENTACAO.pdf >. Acesso em: 12 set. 2016.

BRASIL. Ministério da Educação e do Desporto. Secretaria de Educação Fundamental.

Parâmetros Curriculares Nacionais: Matemática - terceiro e quarto ciclos do Ensino Fundamental. Brasília: MEC/SEF, 1998. Disponível em:

<http://portal.mec.gov.br/seb/arquivos/pdf/matematica.pdf>. Acesso em: 12 set. 2016.

GIL, A. C. Métodos e Técnicas de Pesquisa Social. 6. ed. São Paulo: Atlas, 2008.

LINS, R.; GIMENEZ, J. Perspectivas em Aritmética e Álgebra para o século XXI. 2. ed. São Paulo: Papirus, 1997.

RIGOTTI, J. I. R. Variáveis de educação dos censos demográficos brasileiros de 1960 a 2000. In: RIOS-NETO, E. L. G.; RIANI, J. L. R. Introdução à demografia da educação. Parte II - Bases de dados educacionais. Campinas: ABEP, 2004. Disponível em:

<http://www.abep.nepo.unicamp.br/docs/outraspub/demoedu/parte2cap3p129a142.pdf>. Acesso em: 12 set. 2016. 
SÃO PAULO (Estado). Secretaria da Educação. Coordenadoria de Estudos e Normas Pedagógicas. Proposta Curricular para o ensino de Matemática: Ensino Fundamental. $5^{\mathrm{a}}$ ed. São Paulo: SE/CENP, 1997.

SÃO PAULO (Estado). Secretaria da Educação. Caderno do Professor: Matemática, Ensino Fundamental $-6^{\text {a }}$ série, volume 4. São Paulo: SE, 2009.

SÃO PAULO (Estado). Secretaria da Educação. Currículo do Estado de São Paulo: Matemática e suas Tecnologias - Ensino Fundamental - Ciclo II e Ensino Médio. São Paulo: SE, 2010.

SÃO PAULO (Estado). Secretaria da Educação. Currículo do Estado de São Paulo: Matemática e Suas Tecnologias - Ensino Fundamental - Ciclo II e Ensino Médio. $1^{\text {a }}$ edição atualizada. São Paulo: SE, 2011.

SÃO PAUlO (Estado). Secretaria da Educação. Currículo do Estado de São Paulo: Matemática e suas tecnologias. São Paulo: SE, 2012.

SÃO PAULO (Estado). Secretaria da Educação. Escola de Formação e Aperfeiçoamento dos Professores "Paulo Renato Costa Souza" (EFAP). Regulamento do Programa Currículo e Prática Docente - 2012. São Paulo: EFAP, 2012a. Disponível em:

<http://www.rededosaber.sp.gov.br/portais/Portals/101/regulamento_cpd_2012.pdf>. Acesso em: 12 set. 2015.

SÃO PAULO (Estado). Secretaria da Educação. Escola de Formação e Aperfeiçoamento dos Professores "Paulo Renato Costa Souza" (EFAP). Relatório de Aprovação do Curso Currículo e Prática Docente - Matemática - 2012 (Extraído do AVA-EFAP em 8 de janeiro de 2016 às 11h06min33s). São Paulo: EFAP, 2016.

SHULMAN, L. S. Those who understand: knowledge growth in teaching. Educational Researcher, 15 (2), p. 4-14. 1986.

USISKIN, Z. Concepções sobre a álgebra da escola média e utilizações das variáveis. In: COXFORD, A. F.; SHULTE, A. P. (org.). As ideias da álgebra. São Paulo: Atual, 1995.

ZEICHNER, K. Formação reflexiva de professores: idéias e práticas. Lisboa: Educa, 1993. 